\title{
Influence of submerged groynes for urban creek rehabilitation on aquatic environment at Sawmill Creek in Ottawa, Canada
}

\author{
M. A. Ruta ${ }^{1}$, E. C. Jamieson ${ }^{2}$, C. D. Rennie ${ }^{1}$, \\ R. D. Townsend ${ }^{1} \&$ B. Bezaire ${ }^{3}$ \\ ${ }^{1}$ Department of Civil Engineering, University of Ottawa, Canada \\ ${ }^{2}$ Water Survey of Canada, Environment Canada, Canada; previously \\ with University of Ottawa, Canada \\ ${ }^{3}$ City of Ottawa, Canada
}

\begin{abstract}
Submerged groynes (low-profile linear rock structures, also called stream barbs) were installed in a reach of Sawmill Creek in Ottawa, Canada in order to mitigate outer bank erosion in two consecutive bends. These structures have had an effect on both the aquatic life and habitat in the area. Changes in both the flow field and bathymetry have been recorded over 4 years (including 2 years prior to implementation of the groynes) using acoustic Doppler velocimeters, an acoustic Doppler current profiler, and a total station, respectively. The City of Ottawa's Water Environment Protection Program (WEPP) has also provided fish abundance and habitat data for the study site as well as a control site located approximately $200 \mathrm{~m}$ downstream. The velocity and bathymetry data collected, combined with the fish abundance data, were used to demonstrate a causal relationship between the implementation of submerged groynes and the recorded change in fish abundance and habitat. There has been a consistent increase in fish abundance at the study site compared to that of the control site, indicating that the presence of the groynes is beneficial to the aquatic environment. This could be attributed to select features provided by the groynes which were not inherently available at the study site, namely: (1) velocity refuge and (2) visual isolation from predators.

Keywords: barb, submerged groyne, urban creek, rehabilitation, fish abundance.
\end{abstract}




\section{Introduction}

Urban creeks are areas of high importance for channel rehabilitation because increased run-off from urban watersheds can cause large fluctuations in channel flow rate following heavy rainfall events. This paper reports a study of the influence of an urban channel rehabilitation project on fish populations and habitat. The initial purpose of the project was to aid in the mitigation of stream bank erosion through the installation of submerged groynes in the area. Submerged groynes (barbs) are low-profile rigid hydraulic structures that extend from the river bank into the flow. They are generally used to divert high velocity flow towards the center of the channel. They are a variation of a groyne, such that they are designed to be regularly overtopped, similar to spur dikes.

Studies have shown that fish populations tend to react positively towards areas of velocity refuge, visual isolation, overhead cover, and increased depth (Fausch [1], Pretty [2]). Shields ([3]) found that utilization of barb-type structures results in side effects such as increased channel width, low-velocity pools, and increased channel depth. These types of characteristics have been found to be beneficial and allow for the support of higher levels of fish biomass (Shields [4]).

The barb installation design for this project was reported by Jamieson [5]. Initial evaluation of the influence of barb installation on channel hydraulics and morphology was described in Jamieson [6, 7]. This paper reports updated results regarding the effects of submerged groyne rehabilitation on the aquatic environment of an urban creek through the use of recently available flow velocity and bathymetry data, as well as fish abundance and habitat assessments provided by the City of Ottawa's Water Environment Protection Program (WEPP).

\subsection{Site information}

Sawmill Creek in Ottawa, Canada has a total watershed area of $27.7 \mathrm{~km}^{2}$ and an approximate length of $10 \mathrm{~km}$ (Parish Geomorphic [8]). A 50m section of Sawmill Creek was chosen for stream bank rehabilitation. The section consists of two bends which were experiencing excessive erosion due to large and rapid fluctuations in discharge and water depth following heavy rainfall, which can be attributed to its highly urbanized watershed. It is this excessive erosion as well as its proximity to structures that made it ideal for the submerged groyne rehabilitation pilot project. Overall, seven barbs were built at the field site (three in Bend 1 and four in Bend 2; Figure 1(a)) and twenty four transects were used for consistent data collection. Location and identification of "as built" barbs and transects are shown in Figure 1(b).

\section{Data collection}

Two instruments were used to characterize the flow field in the creek: the M9 RiverSurveyor acoustic Doppler profiler (ADP) by SonTek, and the Vectrino acoustic Doppler velocimeter (ADV) by Nortek. 

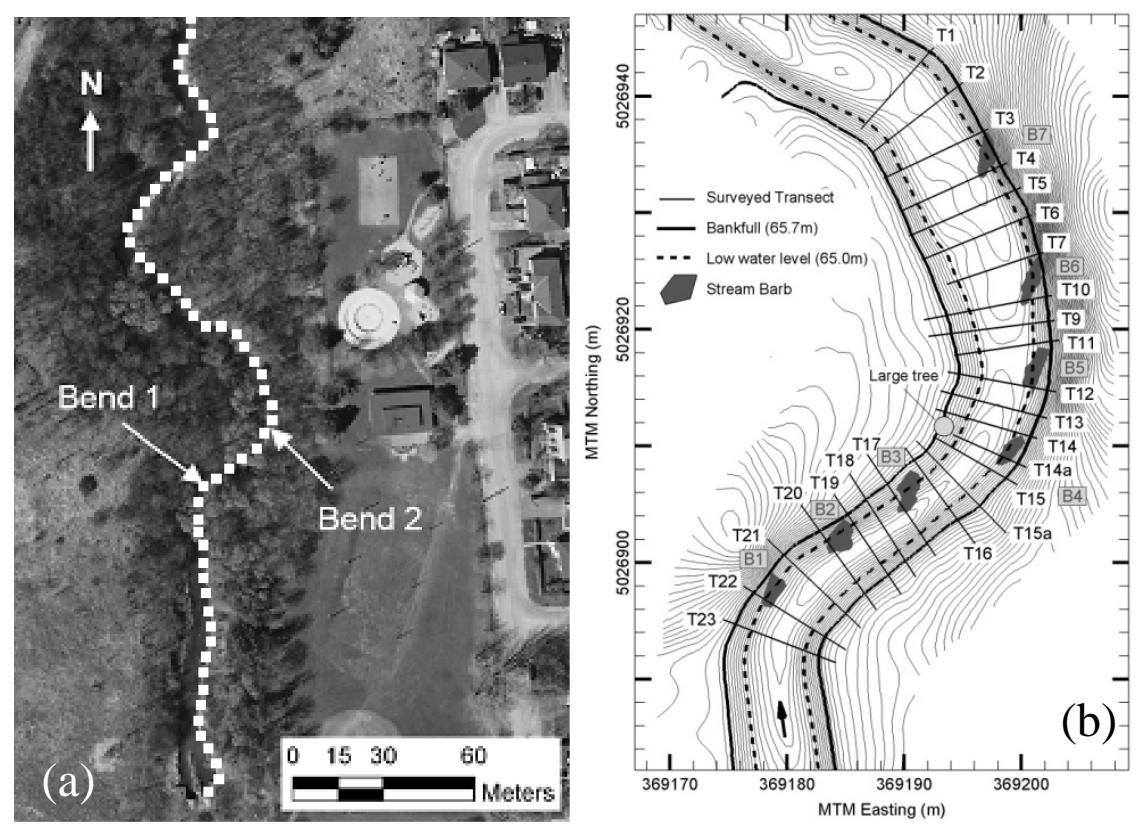

Figure 1: (a) Aerial photograph of the Sawmill Creek study area, where the dashed line indicates the right bank and flow is from south to north (from Jamieson [5]. (b) "As built" barb placement and identification of transects for data collection (from Jamieson [7]).

ADVs were employed to capture detailed three-dimensional flow features and turbulence data at a cross section upstream of the first barb (T22, Figure 1(b)). These data were collected prior to- and post implementation of the barbs: May 11, 2009 and June 4, 2012 respectively. To collect the data as quickly as possible, three ADVs were used simultaneously while mounted to a temporary platform spanning the channel (Figure 2(a)). The measured 3-D velocity and turbulence data are representative of a single point. Therefore, in order to characterize the cross section sampling, verticals were spaced approximately $0.5 \mathrm{~m}$ apart with more than 10 samples collected per vertical and with an increased resolution near the bed. At each of these sampling points, data were collected at $200 \mathrm{~Hz}$ for a period of 2 minutes. Samples were then processed using Matlab to yield mean 3-D velocities and turbulent flow statistics (see Jamieson [9]). These data were then further processed in Tecplot in order to interpolate continuous contours over the entire cross section for both pre- and post-barb implementation.

ADPs were used to map the 3-D flow field and depth of the study site through the first bend. The ADP used has a 9 beam system: two sets of four profiling beams (one set with a $3 \mathrm{MHz}$ frequency and the second set with a $1 \mathrm{MHz}$ frequency), and a vertical beam for measuring depth (Figure 2(b)). The instrument was mounted to a small tethered boat (Figure 2(c)) which travelled in 
a zig-zag pattern down the channel. In order to track the position of the instrument while moving throughout the stream, the ADP was integrated with a real-time kinematic Global Positioning System (RTK-GPS). However, due to the study site being located in a heavily wooded area it was difficult to produce reliable GPS data because of the lack of visibility to available satellites. Therefore the ADP surveys were referenced according to bottom tracking provided by the SonTek software (SonTek/YSI [10]). Further details on the ADP surveying and data processing procedures are available elsewhere in Jamieson $[6,7]$.
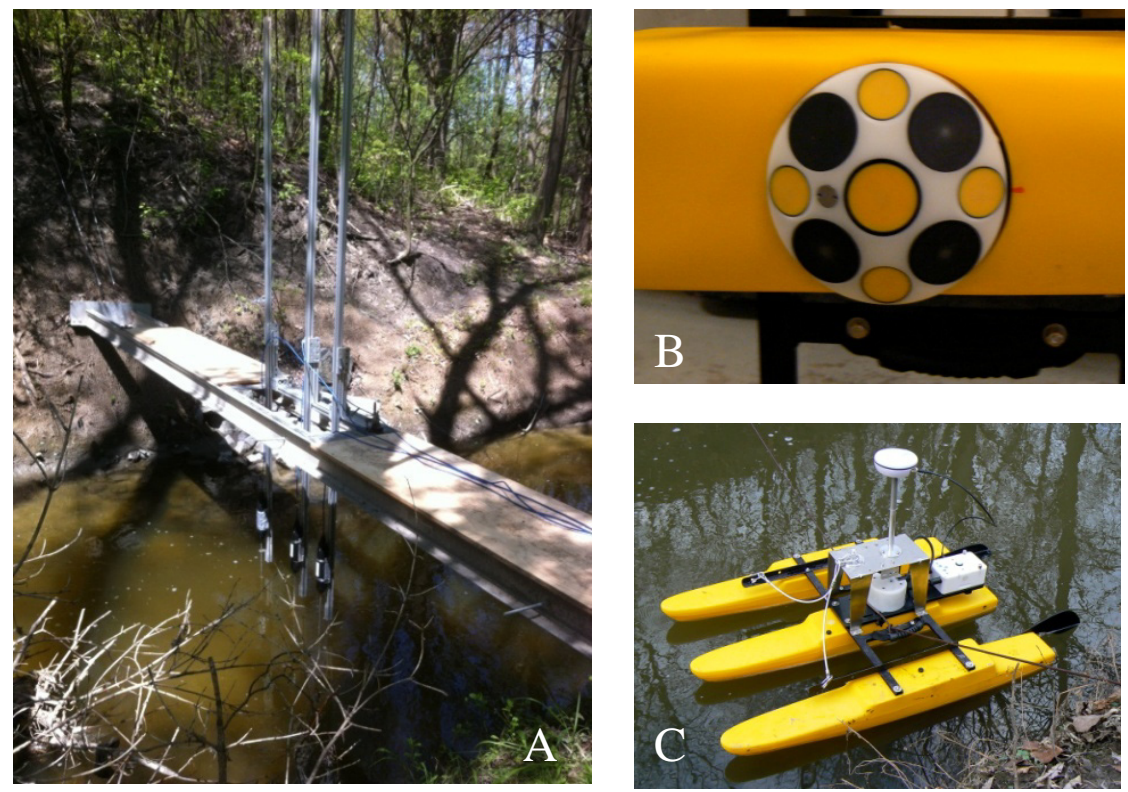

Figure 2: (A) ADV configuration on temporary bridge at transect T22; (B) Sensor layout of ADP; (C) ADP boat configuration with GPS.

Fish abundance and habitat data were provided by the City of Ottawa's Water Environment Protection Program (WEPP) (City of Ottawa [11, 12]). The data were collected at both the barb study site (CK18-Y) and a control site located 200m downstream (CK18-X). The control site allows for a comparative assessment of the effects of the implementation of submerged groynes on the aquatic environment. Changes in available fish habitat due to barb installation were assessed using point transect sampling. The point transect sampling was completed following the channel morphology module of the Ontario Stream Assessment Protocol and involves establishing transects perpendicular to the flow throughout the site and taking measurements at points along these transects (Stanfield [13]). Measurements include information on depth, water velocity, cover, substrate composition and diversity, and degree of undercutting. Both the 
control site and the pre-installation barb reach were surveyed in 2008, and the barb reach was surveyed again following barb installation in 2009.

Fish population surveys in both the control and study reaches span over 5 years, including one year of pre-barb installation (2008) and three years post implementation (2010, 2011, and 2012). Fish captures were conducted using electrofishing. This technique involves sending an electric current into the water from a backpack electrofishing unit, against which fish involuntarily swim. As the fish swim towards the source of the current, they are caught with a net, identified, counted and weighed. Once all necessary data are collected on the specimen, the fish are returned to the creek unharmed (City of Ottawa [11]). Sampling was carried out at the same time every year (early to mid July) except in 2010 where the community sampling took place in mid to late August. It would have been preferential that the sampling was taken multiple times throughout the summer season in order to account for any seasonal fluctuations. For this reason it is unclear as to whether the later sampling in 2010 had an effect on the collected data set.

\section{Results and discussion}

\subsection{Flow field}

\subsubsection{ADP}

Pre- and post-barb spatially distributed velocity fields measured by ADP spatial surveying were shown in Jamieson $[6,7]$. Here we assess the relevance of the observed spatial velocity distributions for fish habitat. The collected data consisted of one pre-barb installation survey (2009-09-09) and 5 post-barb installation surveys. It should be noted that due to limitations in available depth to deploy the ADP, the spatial surveys focus on the upstream bend. The first (2009-09-09) survey was indicative of the pre-barb installation and it demonstrated that the core of maximum velocity was along the outer (left) bank (downstream of T22) with maximum velocity located at the bend exit. Although measurements were taken at varying discharges, certain spatial trends exist in the post-barb implantation surveys.

For all surveys with barbs (2009-11-21 through 2011-10-21) it can be seen that there is a general shift of the high velocities towards the centre of the channel. This results in having a reduced velocity magnitude along the outer bank of the bend. Furthermore, the velocity vectors show that these areas of low velocity between the barbs are recirculation cells. In regards to providing zones of velocity refuge and sources of food for aquatic species, these flow recirculation areas between the barbs are considered to be ideal. This is because of the proximity of the flow recirculation areas to the high velocity field in the channel centre thalweg. Fish resting in the flow recirculation areas have easy access to invertebrate species being transported in the channel centre (Fausch [1]). Since this observed shift of the high velocity field is viewed in all post barb implementation surveys, it can be said that the shift is caused by the presence of the barbs. 


\subsubsection{ADV}

The mean velocity field across the T22 transect measured using the ADVs both pre- and post-barb installation is shown in Figure 3. Transect T22 is situated across the toe of the first barb in the first bend (Figure 1(b)). The barb was physically situated at the outer (left) bank in the post-barb flow field, thus the extrapolated flow field in this region should be ignored. Note that discharge and water surface elevation were lower in the post-installation measurements, but comparison of the two surveys still allows for assessment of influence of the barbs on the flow field. In the pre-barb flow field, the high velocity core was located nearer the inner bank (see discussion in Jamieson [6]). The post-barb data suggest that the high velocity core is now situated over the centre of the channel, adjacent to the barb, and possibly the barb itself has impeded further outward migration of the high velocity core (Figure 3(b)). Shift of the high velocity core to the channel centre may be due to topographic steering resulting from scour of the channel centre, whereby flow is forced into the deeper part of the channel. Before the barbs were installed there was a strong centrally-located secondary circulation cell (Figure 3(a)). Such a cell is typical of bend flows, with secondary flow toward the outer bank at the top of the flow, and toward the inner bank near the channel bottom. The cell was particularly strong, with secondary velocities as large as $1 / 3$ the magnitude of the streamwise velocities. Similarly strong secondary velocities were observed in the post-barb condition. It appears, however, that the secondary circulation cell is disrupted in the post-barb condition. The secondary flow is now largely toward the outer bank, except near
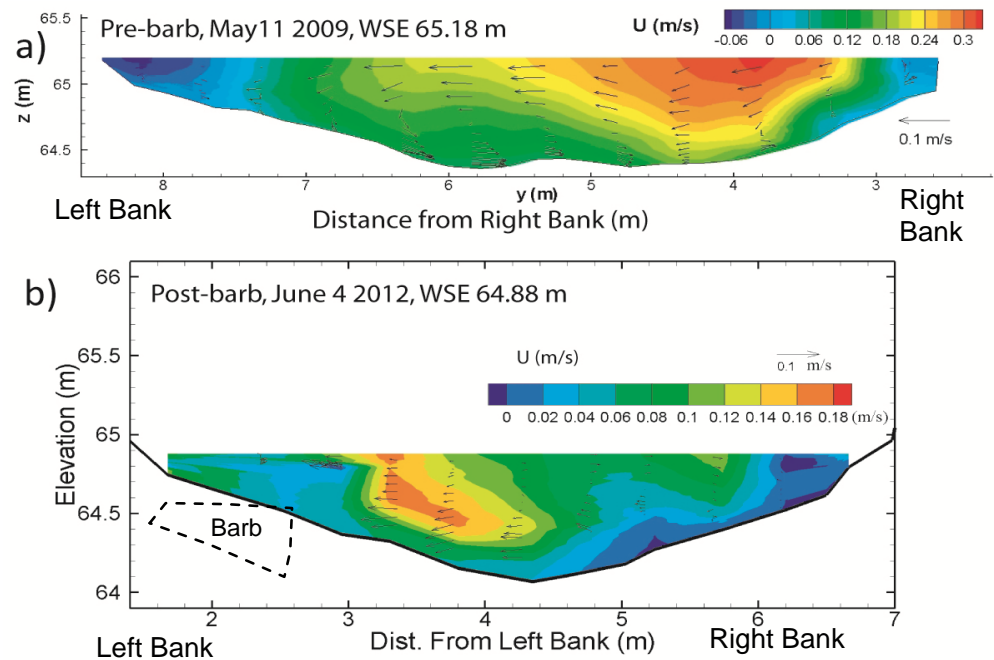

Figure 3: $\quad$ Transect 22 mean velocity distribution, (a) pre-barbs, (b) post-barb installation. WSE is water surface elevation at time of measurement. Colour contours indicate interpolated streamwise velocity, vectors indicate secondary velocities at ADV measurement locations. Note the difference in colour scale between (a) and (b). 
the inner-bank where a region of flow circulation is evident. The shift of the secondary circulation cell may in part be due to the influence of woody debris that fell into the channel from the inner bank upstream of the first bend subsequent to barb installation. Importantly, it is evident that the barb has completely disrupted the secondary velocities near the outer bank, which is one of the reasons why barbs can reduce outer bank erosion.

\subsection{Bathymetry}

Annual topography data were collected over four years (2009-2012) at each transect using a Total Station such that any discernible changes to bed and/or bank topography would be recorded. In general, more significant changes to the bed were observed in the area of the first bend, with little to no change in bathymetry being observed through the second bend. As a result, it is the region around the first bend that will be discussed in more detail. Recorded crosssectional data for the first bend (T22-T15a) are presented in Figure 4. Overall, it can be seen that in the upstream sections there exists continuous erosion in the thalweg center of the channel. At section T22, up to $\sim 0.2 \mathrm{~m}$ of bed level drop occurred between 2009 and 2010 and then another drop of up to 0.1 m occurred between 2010 and 2012. Similarly at sections T20 and T19, measurements show a maximum drop $0.2 \mathrm{~m}$ from 2009 to 2010, and slightly lower drop from 2010 to 2012 (up to $\sim 0.15 \mathrm{~m}$ ). The largest change in bed level occurred at section T21 from 2010 to 2012. This area showed a maximum bed level drop of $\sim 0.5 \mathrm{~m}$ despite having only shown a maximum change of $\sim 0.1 \mathrm{~m}$ between 2009 and 2010. Section T21 is immediately downstream of the apex of the first bend, and it appears that the minimal constriction of the channel imposed by the barbs

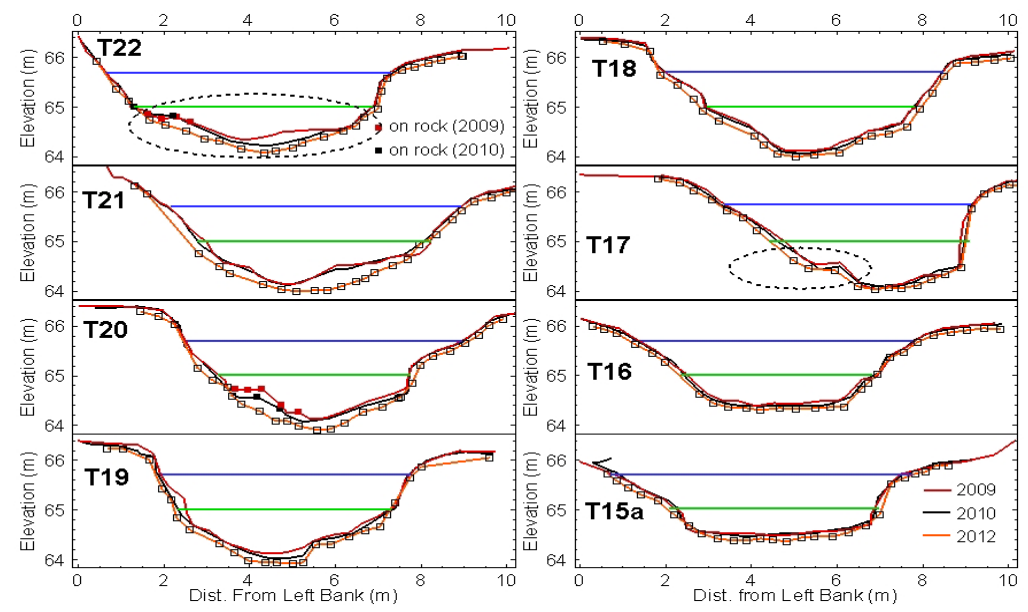

Figure 4: Cross-sectional view of transects taken throughout the first bend (T22-T15a) for 3 years: 2009, 2010, 2012. The 2012 data are labelled with open symbols. The measurements from 2011 are not included due to a lack of density of measured points. Locations of the measured transects can be seen in Figure 1(b). 
had greatest effect here. Further downstream (T18 to T15a), little to no erosion is visible from 2009 to 2010, however the small change in bed level from 2010 to 2012 (in the order of $\sim 0.1 \mathrm{~m}$ ) appears to be almost uniform along the bed and banks but returns to 2010 levels in the floodplains. Importantly, the location of the maximum erosion occurred at the center of the channel throughout the bend (Figure 4). This demonstrates that the barbs in the first bend (more predominantly visible in the area of the first barb (B1; transects T22 and T21)) were successful in scouring the center of the channel, creating deeper pools and aiding in the channel stability.

It should be noted that locations of rocks at T22 and T20 are not present for the 2012 measurements due to acts of vandalism at the study site. Transect markers were removed along the left bank (at T22, T20, and T19), and were therefore in need of replacement. These new markers were placed such that the transects remained perpendicular to the curvature of the channel, and as close to the original positions as possible. However, it appears that these new placements caused the measurements to be taken just upstream of the groynes as opposed to just over the tip as was done in previous years. This slight misalignment of survey points could account for some of the differences in bed levels. Still, transect T22, T20, and T19 results are consistent with those observed at the undisturbed sections, thus errors due to the disturbance were likely small.

Daily mean, minimum and maximum discharge, for the previous four seasons (2008-2011), are provided in Jamieson [6]. These data demonstrate the seasonal variability and the large and rapid fluctuations in discharge and water level that Sawmill Creek experiences following heavy rainfall events. These data are useful when interpreting some of the annual changes in bathymetry.

\subsection{Fish habitat}

The results of the point transect habitat assessment (Table 1) reveal that barb installation increased available pool and cover habitat in the barb study site. It is worth noting that even before the addition of barbs, there was more pool and cover habitat available at the barb site than the control site.

\subsection{Fish abundance}

Results of the fish community sampling are shown in Figure 5 and Table 2 below. Overall, the results show that post-installation there has consistently been an increase in fish abundance at the barb study site when compared to the control site (Figure 5). As only one year of before-installation data are available, it is not possible to calculate mean values for total fish abundance in both reaches prior to barb construction. Therefore total fish abundance values from the barb site are directly compared to the values gathered from the control site in the same year. Before barb installation, the barb site had less than half (33\%) of the total fish abundance found at the control site (Figure 5, Table 2). However, following barb construction (in 2009), the relative abundance at the field site increased to $63 \%$ in 2010 and similarly to $71 \%$ in 2011 and $70 \%$ in 2012. In addition to the relative increase in fish abundance at the barb site, an increase in species richness was also observed. Prior to barb construction, the Central Mudminnow, Brook 
Stickleback or Rock Bass were not present at either of the barb or control sites. They were, however, present in at least one or more of the collected data sets for the barb site post barb construction.

Table 1: $\quad$ Transect habitat assessment results for control site (CK18-X) and barb study site (CK18-Y) pre- and post-installation. (City of Ottawa $[9,10])$.

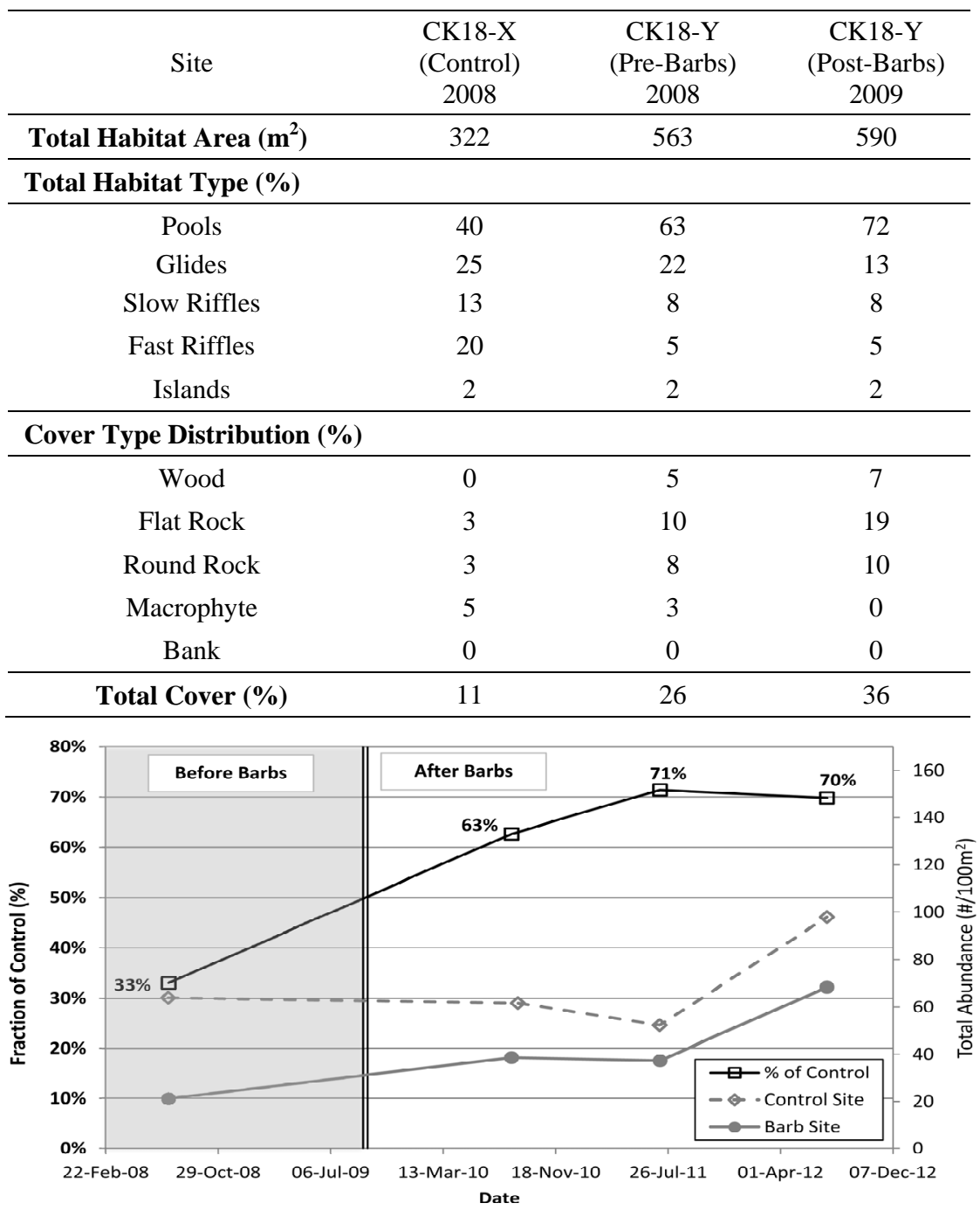

Figure 5: Increase in total fish abundance at the Barb site as a fraction of the Control (primary axis), with total fish abundance $\left(\# / 100 \mathrm{~m}^{2}\right)$ at both the Barb and Control Site (secondary axis). (See Table 2 for complete results). 


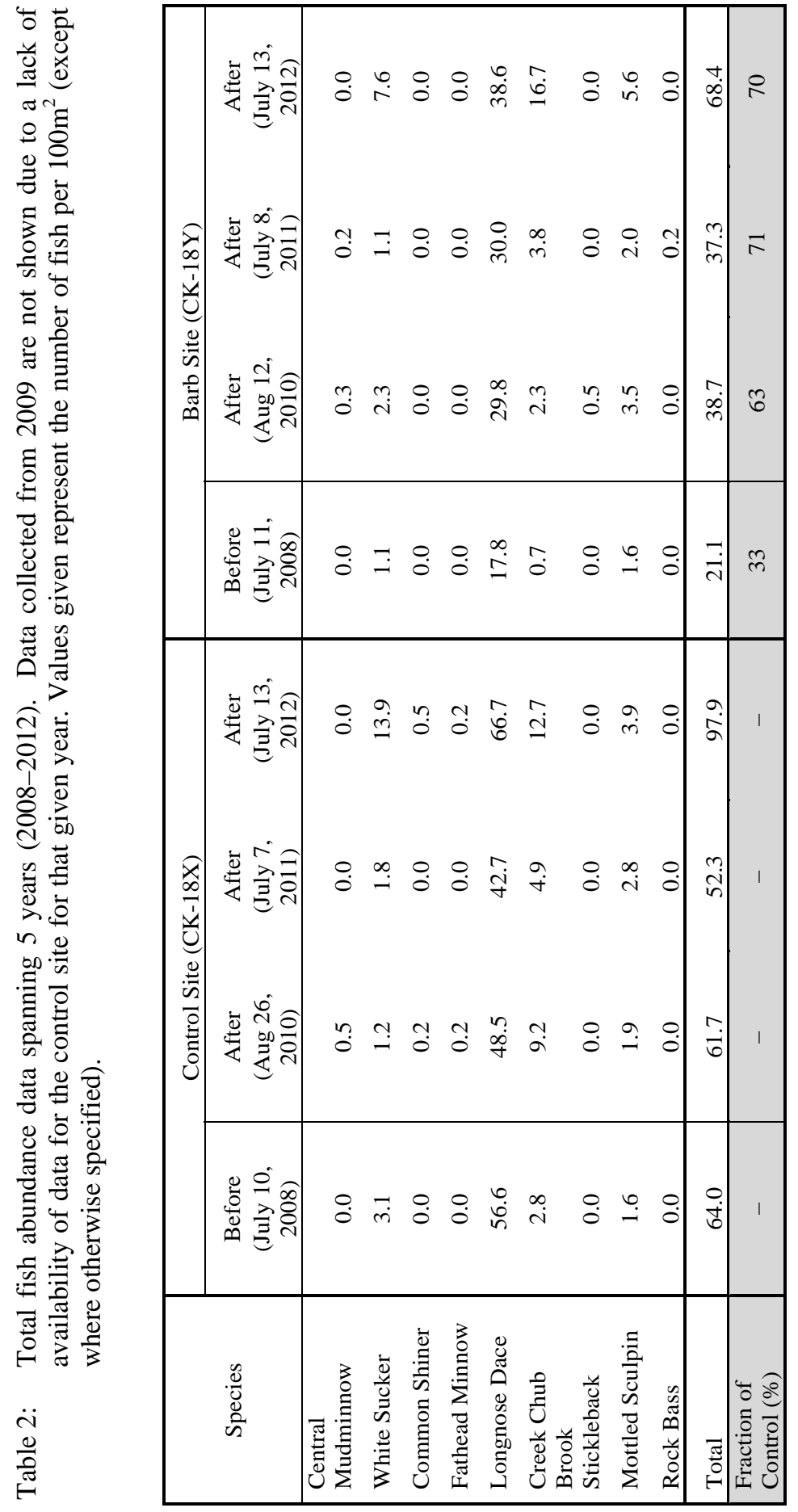

WIT Transactions on Ecology and The Environment, Vol 172, (C) 2013 WIT Press www.witpress.com, ISSN 1743-3541 (on-line) 


\section{Conclusions}

This study examined the influence of channel rehabilitation involving submerged groyne (barb) series in channel bends on the flow field, bed morphology, fish habitat, and fish populations. The barb study reach was monitored for these variables before and after barb installation, and a nearby control reach was monitored for fish habitat and populations over the same period. Post-installation surveys indicate that the barbs successfully shifted channel erosion from the outer bank to the channel centre, resulting in a deeper thalweg. This may in part be due to disruption of the main secondary flow recirculation cell. The barb series provided zones of flow recirculation that are useful flow refugia. Overall, the barbs increased available pool and cover fish habitat. The increased habitat may have been why fish abundance and species richness increased in the barb reach as compared to the control reach.

\section{References}

[1] Fausch, K. D., Experimental analysis of microhabitat selection by juvenile steel head (Bncsshynchus mykiss) and coho salmon (0. kisuteh) in a British Columbia stream. Can. J. Fish. Aquat. Sci., 58, pp. 11 98-1 207, 1993.

[2] Pretty, J.L. et al., River rehabilitation and fish populations: assessing the benefit of instream structures. Journal of Applied Ecology, 40, pp. 251-265, 2003.

[3] Shields, Jr., F.D., Knight, S.S. and Cooper, C.M., Addition of spurs to stone toe protection for warmwater fish habitat rehabilitation. Journal of the American Water Resources Association, 34(6), pp. 1427-1436, 1998.

[4] Shields, Jr., F.D., Knight, S.S. and Cooper, C.M., Warmwater stream bank protection and fish habitat: a comparative study. Environmental Management, 26(3), pp. 317-328, 2000.

[5] Jamieson, E., Rennie, C.D., Townsend, D.R.. (2009) Design of stream barbs for field scale application at Sawmill Creek, Ottawa, River Basin Management V, Malta, (ed.) Brebbia, WIT Press, pp. 281-292, 2009.

[6] Jamieson, E.C., Ruta, M.A., Rennie, C.D., Townsend, R.D., Monitoring stream barb performance in a semi-alluvial meandering channel: flow field dynamics and morphology. Accepted to Ecohydrology, January 2013.

[7] Jamieson, E.C., Rennie, C.D., Townsend, R.D. Stream barb performance in a semi-alluvial meandering channel, River Basin Management VI, edited by C.A. Brebbia, WIT Press, pp. 227-328, 2011.

[8] Parish Geomorphic, Sawmill Creek Monitoring: Final Report. January, 2005.

[9] Jamieson, E.C., Post, G., Rennie, C.D., Spatial variability of threedimensional Reynolds stresses in a developing channel bend. Earth Surface Processes and Landforms, 35, pp. 1029-1043, 2010.

[10] SonTek/YSI, RiverSurveyor S5/M9 System Manual. 2010.

[11] City of Ottawa, Sawmill Creek Fish \& Fish Habitat Assessment Report 2008. Prepared by the Water Environment Protection Program, Strategic 
and Environmental Services, Environmental Services, Infrastructure Services and Community Sustainability, City of Ottawa, 2009.

[12] City of Ottawa, Sawmill Creek Fish \& Fish Habitat Assessment Report Addendum - 2009. Prepared by the Water Environment Protection Program, Strategic and Environmental Services, Environmental Services, Infrastructure Services \& Community Sustainability, City of Ottawa, 2009.

[13] Standfield, L. (Ed). Ontario stream assessment protocol. Version7, Fish and Wildlife Branch. Ontario Ministry of Natural Resources. Peterborough, Ontario, 2005. 